Signal \& Image Processing : An International Journal (SIPIJ) Vol.3, No.2, April 2012

\title{
RED BLOOD CELLS ESTIMATION USING HOUGH TRANSFORM TECHNIQUE
}

\author{
Nasrul Humaimi Mahmood and Muhammad Asraf Mansor \\ Department of Biomedical Instrumentation and Signal Processing, \\ Faculty of Health Science and Biomedical Engineering, \\ Universiti Teknologi Malaysia, Johor, MALAYSIA \\ nasrulefke.utm.my \\ asraf112358@gmail.com
}

\begin{abstract}
The number of red blood cells contributes more to clinical diagnosis with respect to blood diseases. The aim of this research is to produce a computer vision system that can detect and estimate the number of red blood cells in the blood sample image. Morphological is a very powerful tool in image processing, and it is been used to segment and extract the red blood cells from the background and other cells. The algorithm used features such as shape of red blood cells for counting process, and Hough transform is introduced in this process. The result presented here is based on images with normal blood cells. The tested data consists of 10 samples and produced the accurate estimation rate closest to $96 \%$ from manual counting.
\end{abstract}

\section{KEYWORDS}

Red blood cells, MATLAB, Hough Transform, Morphological Image Processing.

\section{INTRODUCTION}

The erythrocytes are the most numerous blood cells in the human body, and it also called red blood cells. The red blood is a blood that functioned as carry oxygen throughout our body [1]. According to American Cancer Society (2009), the normal red blood cell in our body is divided into four categories of ages, which are newborn, children, women and men. The average amount of red blood cells each category is about 4.8-7.2 million per cubic millimeter, about 3.8-5.5 million per cubic millimeter, about 4.2-5.0 million of these cells per cubic millimeter and 4.6-6.0 $\mathrm{x} 106$ per cubic millimeter respectively. Red blood is measured by the amount of hemoglobin in our blood. The level of hemoglobin in our blood will affect our health tremendously. We suffered fatigue and short of breath when the level of hemoglobin is too low due to not enough oxygen supply to our tissues. This so called Anemic can be relieved with a blood transfusion or with medication to increase our body's production of red blood cells [2]. The effect of having high red blood cells in our blood is it can be an indication of an undetected heart or lung problems. When any of these organs is not functioning properly, then blood oxygen levels go down. In order to normalize oxygen supply, the body increases its production of red blood cells. 
Signal \& Image Processing : An International Journal (SIPIJ) Vol.3, No.2, April 2012

Counting of red blood cells in a blood sample can give the pathologists valuable information regarding various hematological disorders. In the classical method for diagnosis of red blood examination in a blood sample, it is counted by manpower; hence it has deficiencies such as poor reliability, low efficiency and strong subjectivity. The diagnosis is the process of finding out what kind of disease a certain patient has and those diagnosed must always be accurate. A wrong diagnosis may lead the situation and condition of a patient become worst and some case, patient dies due to wrong dosage of drugs given [3]. In order to overcome that weakness, some researchers have done some useful works [4-5] especially in classifying blood cells from other cells, for example, classifying white blood cells from other cells such as red blood cells and platelets [6]. Another example is classifying red blood cells from other cells such as white blood cells and platelets. Most of the researchers have concentrated the classification of white blood cells since most of the disease easy to determine by analysis the changing of white blood cells. However, by counting the red blood cells, it also provided some information about the abnormal condition in our body.

In this paper, we present an approach for counting the number of red blood cells from the blood smear image. There are four steps involved in estimating the red blood cells. These are acquisition, segmentation, feature extraction and estimating. The acquisition step used the existing blood sample images. Next, the segmentation and feature extraction is done by using a morphological technique in order to distinguish the red blood cells from background and other cells. The last step is estimating the number of red blood cells, by using Hough Transform technique [7].

\section{RELATED WORK}

Roy A. Dimayuga et. al [8] used the histogram thresholding to distinguish the nucleus of the leukocyte or white blood cells from the rest of the cells in the image. Ramin Soltanzadeh [9] has purposed feature extraction technique based on morphology in his three blood cell's experiments. Based on morphology of the cells, the mass center of each cell in the images and then find the distance of each pixel on an edge from the center. Heidi Berge [10] has purposed the segmentation red blood cells in a thin blood smear image which is based on the Zack's Method [11]. This method is one of the approached to determine the red blood cells tresholding where a line is drawn between the two peaks and between these two peaks, they used the point which is furthest from the drawn line as a threshold for red blood cell. In the conclusion for this technique, the segmentation result is better to the blood smear which in case red blood cells is sparse and in the image. However, in images with high Red blood cell concentrations, large clumps may result and this method is less accurate. Guitao et. al [12] purposed the Hough transform in detecting and extracting the red blood cells in the urine micrograph. Based on Hough transform, Guitao has used the geometrical feature to detect the circle center in the image.

\section{DESCRIPTION OF THE METHOD}

The basic idea of the red blood cells counting was to use three major techniques which are logical, morphology and Hough transform. 
Signal \& Image Processing : An International Journal (SIPIJ) Vol.3, No.2, April 2012

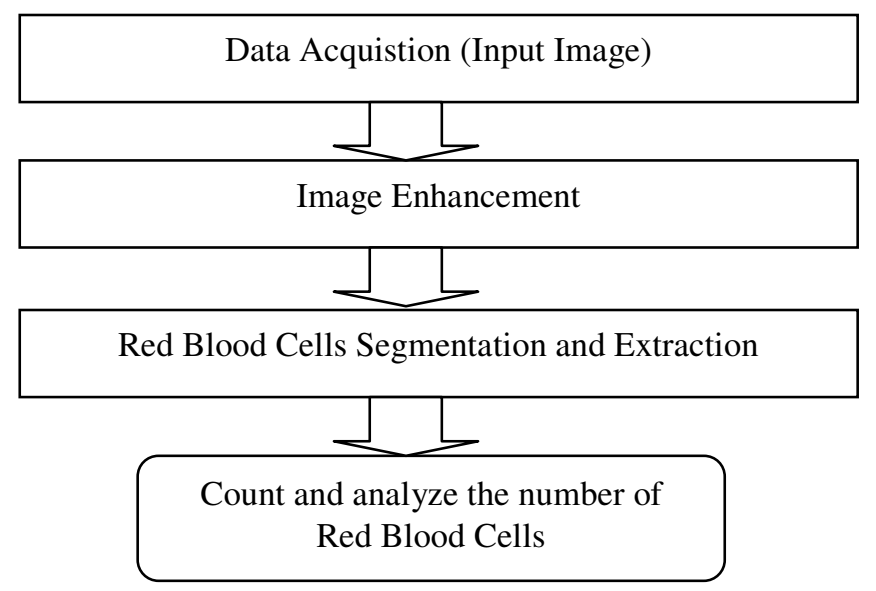

Figure 1: Flow chart of the red blood cells counting process.

Figure 1 shows the flow chart of the red blood cells counting process. In data acquisition, we used sample images from an online medical library [13-15] as an input image and it has shown in Figure 2. These images need to be enhanced for further analysis. This is a pre-process of an image sequence before feeding into the segmentation process. Red blood cells segmentation and extraction is the process to distinguish between red blood cell and other cell in the blood smear image. The last process is counting the number of red blood cells using Hough transform technique.

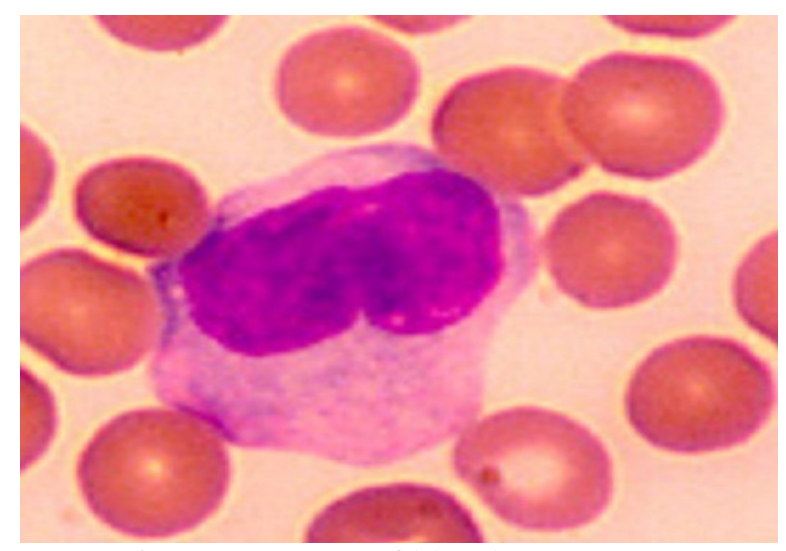

Figure 2: Image of blood smear. [13]

\section{IMAGE ENHANCEMENT}

In image enhancement process, there are two common image processing techniques used in order to reduce the noise and at the same time to enhance the image. Figure 3 shows the flow process in enhancement processing which are analyses in hue-saturation value color space (HSV) and the green component image. For HSV, we proceed with analyses in saturation component, S, because this S image show clearly the bright objects such as white blood cell and parasites, therefore, it's easy to distinguish the red blood cells with another cell. 
Signal \& Image Processing : An International Journal (SIPIJ) Vol.3, No.2, April 2012

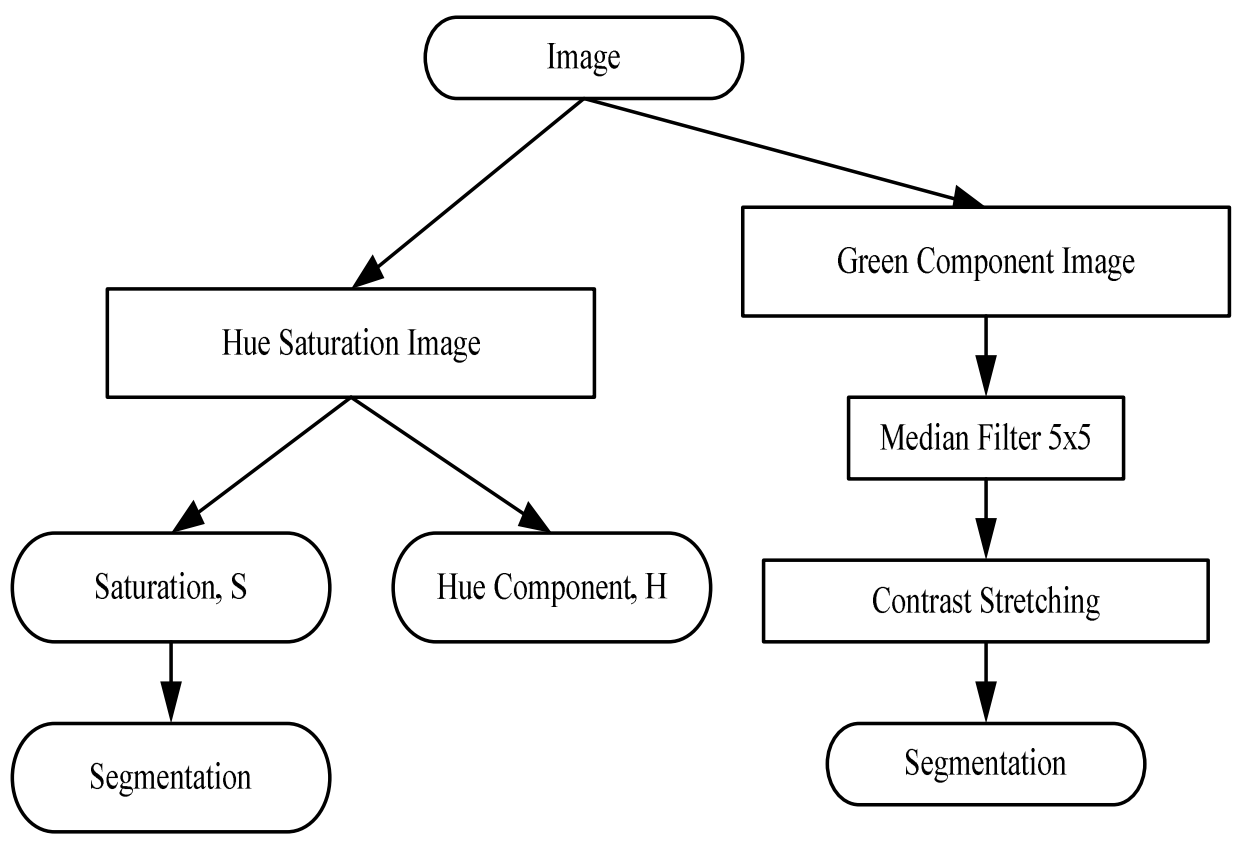

Figure 3: Flow chart of image enhancement.

\section{IMAGE SEGMENTATION AND EXTRACTION}

In the segmentation process, morphological technique is major used because the mathematical morphology offers a powerful tool for segmenting images and useful to describe the region shape, such as boundaries, skeletons and texture. The first method in this process divides saturation, $\mathrm{S}$ image into two images output by applying the thresholding process. Thresholding is one of the methods to extract and segment the object from the background by selecting any point, $\mathrm{T}$.

Any point $(x, y)$ for which $f(x, y)>T$ is called an object point, otherwise the point is called background point. Thresholding normally results in binary image and the mathematically; the operation can be expressed as;

$$
g(x, y)= \begin{cases}1 & \text { if } f(x, y)>T \\ 0 & \text { if } f(x, y) \leq T\end{cases}
$$

where the pixels labeled 1 is corresponded to object whereas the pixels labeled 0 are corresponding to the background.

Figure 4 shows two images with having higher than 0.53 pixel value (lower pixel) and another image is higher than 0.96 pixel value (high pixel). This process is important to distinguish between background and the red blood cells, as well as other cells. 
Signal \& Image Processing : An International Journal (SIPIJ) Vol.3, No.2, April 2012

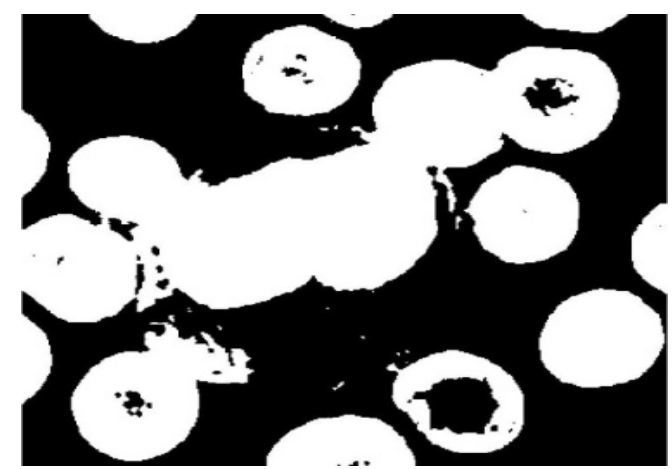

(a)

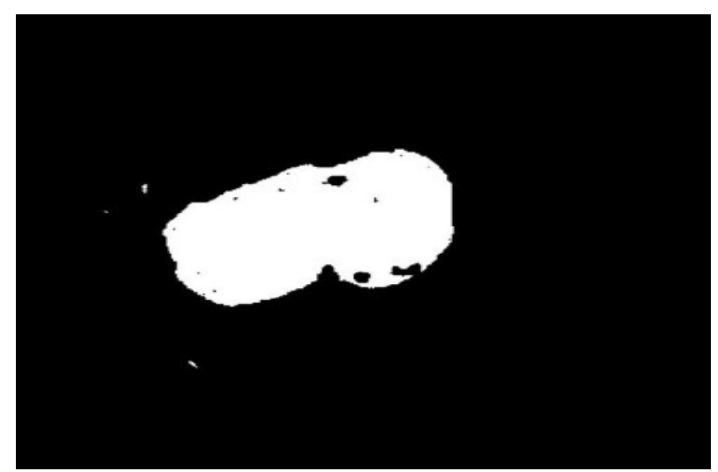

(b)

Figure 4: (a) Image with higher than 0.53 pixel value (lower pixel) (b) Image with higher than 0.96 pixel value (higher pixel).

From the lower pixel image we perform the morphological area closing to fill the hole and eliminate the unwanted small pixel. The other image which is higher pixel value has been used as an input for next processes which are dilation and area closing. Figure 5 shows the area closing on the lower pixel image and higher pixel image. It can be seen that the hole in the cell has been filled up.

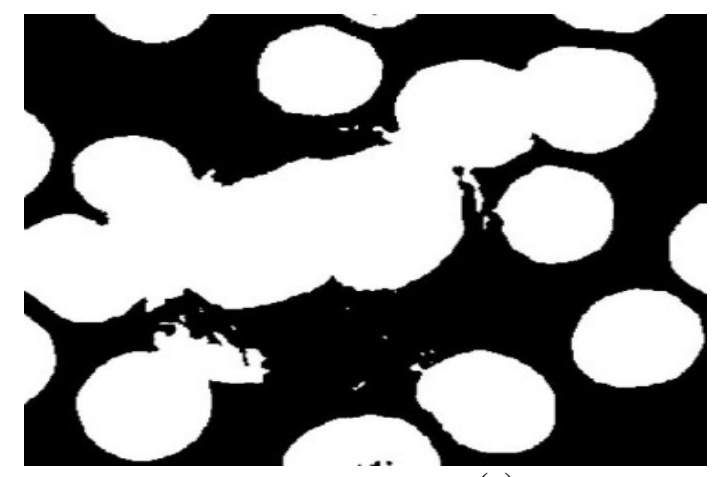

(a)

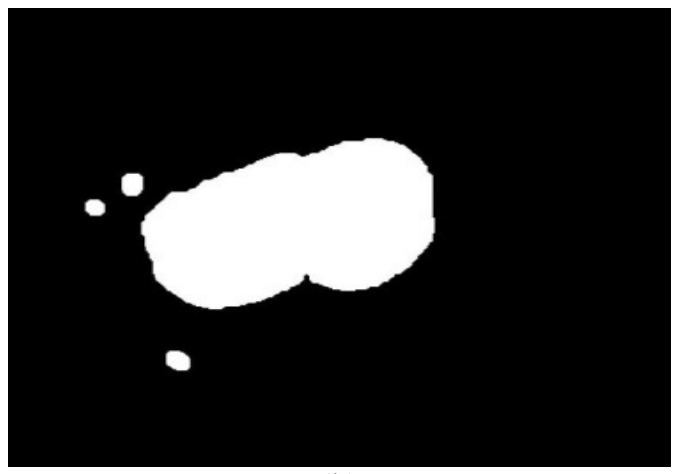

(b)

Figure 5: (a) Morphological area closing on lower pixel value image. (b) Morphological dilation and area closing on higher pixel value image.

From the result after morphological from both lower and higher pixel, the range value of pixel is determined. The histogram is suitable to describe where the position of the range value we want in this work. Histogram of saturation, $S$ image is shown in Figure 6. In this histogram, we want to preserve the image that has higher than 0.53 and less than 0.96 pixels. 
Signal \& Image Processing : An International Journal (SIPIJ) Vol.3, No.2, April 2012

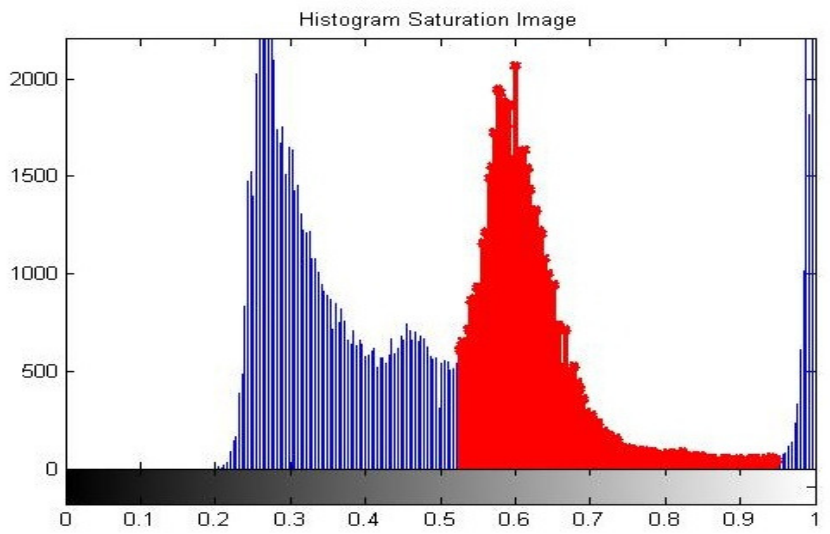

Figure 6: Histogram of saturation, $S$ image.

To preserve the saturation, $S$ image value between 0.53 and 0.96 as highlighted with red in the histogram graph, the XOR and area opening with disk structural element has been introduced. Figure 6 shows the result when XOR operation and area opening with disk structural element introduces to both of result after morphological on lower and higher pixel image. From the result of these two operations, we change the red blood cells from white color to black color and background took a white color. Once again, the XOR operation is used and the resulted image is shown in Figure 7.

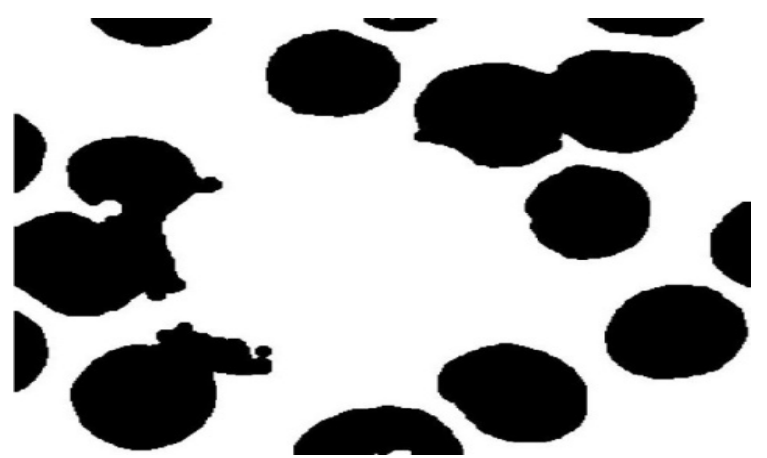

Figure 7: Result of morphological XOR operation.

\section{COUNTING THE NUMBER OF RED BLOOD CELLS}

In order to estimate the number of red blood cells in the blood smear image, some techniques have been proposed. The following techniques such as morphological erosion, median filter and Hough transform are discussed.

By using the result from Figure 7, morphological erosion technique and also median filter with $4 \times 4$ neighborhoods had been applied to this image to eliminate small unwanted pixel and image smoothing. Red blood cells showed by black and background in white. The resulted image was used as an input for Hough transform process. 
Signal \& Image Processing : An International Journal (SIPIJ) Vol.3, No.2, April 2012

The final process in the algorithm of counting the number of red blood cells is to perform Hough transform technique. The Hough transform was initially developed to detect analytically defined shapes such as straight line, circle, as well as the parameter curve [16-18].

This technique is able to detect and estimate the number of red blood cells by determining the center point of the circle. In order to determine the center point, radius of circle is needed and from original image, we found the radius by using the MATLAB function, "IMDISTLINE". In this image the minimum radius is 36 pixels and maximum radius is 40 pixels. Thus, the Hough transform is applied when both radiuses have been determined and the result of this process is shown in Figure 8. Red blood cells have been bounded by green circle and counting process refers to this green circle in this image.

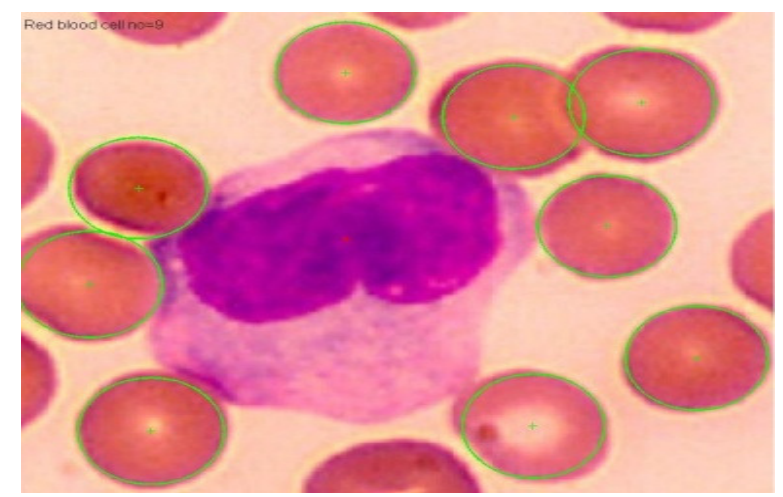

Figure 8: Result of red blood cells estimation.

\section{RESULTS AND DISCUSSION}

The results are presented and the graphical user interface (GUI) is developed to provide user friendly for analysis. This GUI was developed using GUIDE (Graphical User Interface Development Environment) which is one of the tools that have been provided in the MATLAB.

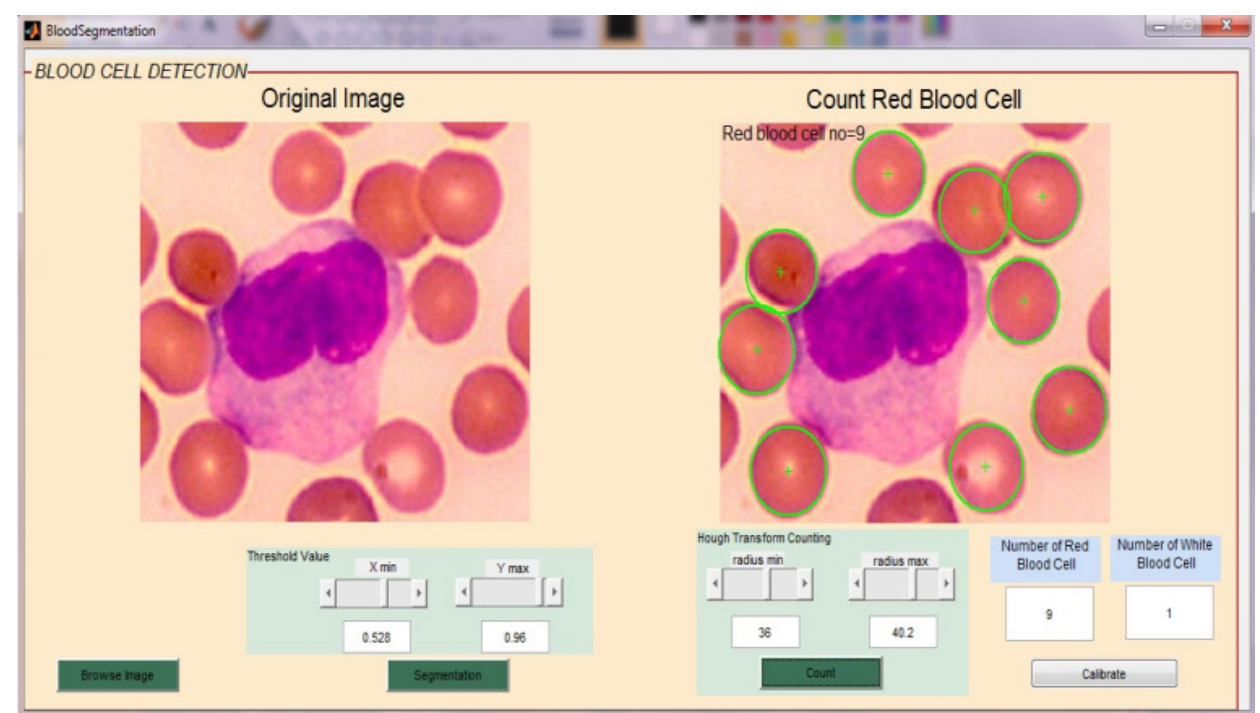

Figure 9: GUI shows a case of estimating number of red blood cells. 
Signal \& Image Processing : An International Journal (SIPIJ) Vol.3, No.2, April 2012

Figure 9 shows the GUI for estimating the number of red blood cells in blood smear image. An important in this estimating process is radius of red blood cells. Each image has different radius that need to determine before proceed to the estimating process. Table 1 presents the radius parameter for each 10 set of images collected from different sources.

Table 1: Training data.

\begin{tabular}{|c|c|c|}
\hline \multirow{2}{*}{ Image } & \multicolumn{2}{|c|}{ Radius } \\
\cline { 2 - 3 } & Mimimum & Maximum \\
\hline 1 & 33 & 40 \\
\hline 2 & 36 & 40 \\
\hline 3 & 37 & 40 \\
\hline 4 & 32 & 40 \\
\hline 5 & 26 & 34 \\
\hline 6 & 15 & 30 \\
\hline 7 & 21 & 28 \\
\hline 8 & 11 & 20 \\
\hline 9 & 18 & 24 \\
\hline 10 & 12 & 18 \\
\hline
\end{tabular}

From this image samples, the average computational time by this system is 3 seconds per sample. The accuracy is measured based on final results produced by the algorithm to refer to the manual counting process. Table 2 shows a comparison between manual counting and estimation by computer for 10 image samples. The average of accuracy of these 10 image samples is $96 \%$.

Table 2: The accuracy of 10 image samples

\begin{tabular}{|c|c|c|}
\hline \multirow{2}{*}{ Image } & \multicolumn{2}{|c|}{ Number of Red Blood Cells } \\
\cline { 2 - 3 } & Manual Counting & Computer Counting \\
\hline 1 & 15 & 15 \\
\hline 2 & 20 & 19 \\
\hline 3 & 37 & 35 \\
\hline 4 & 60 & 59 \\
\hline 5 & 18 & 18 \\
\hline 6 & 34 & 35 \\
\hline 7 & 37 & 35 \\
\hline 8 & 60 & 54 \\
\hline 9 & 102 & 95 \\
\hline 10 & 9 & 9 \\
\hline
\end{tabular}

Figure 10 shows the result of image blood samples by using Hough transform technique. 
Signal \& Image Processing : An International Journal (SIPIJ) Vol.3, No.2, April 2012

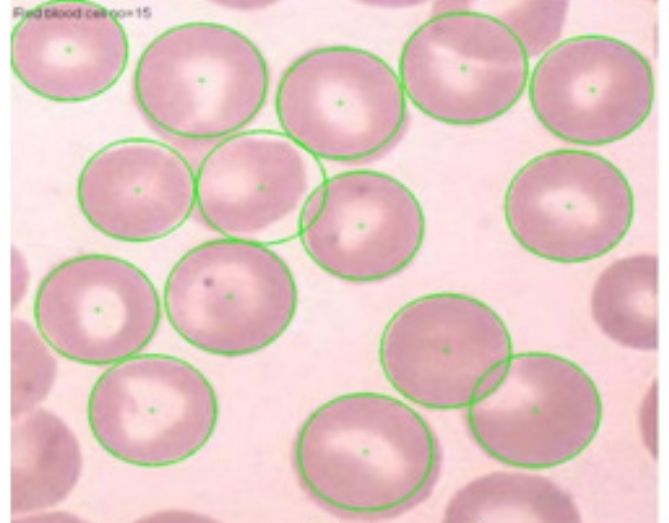

(a) Image 1

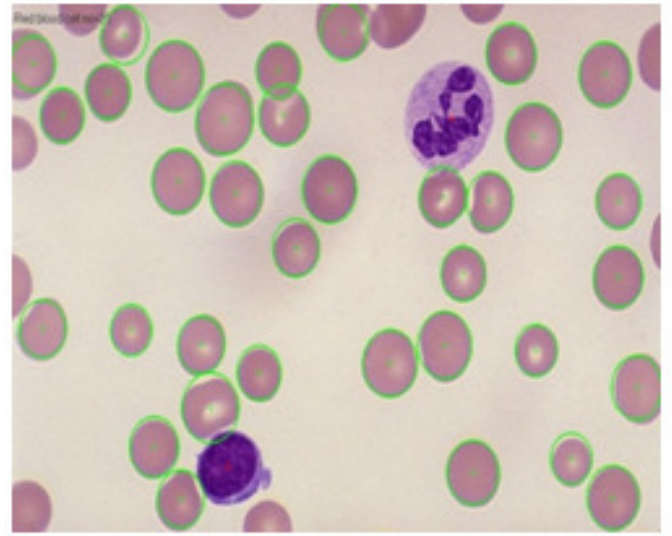

(c) Image 3

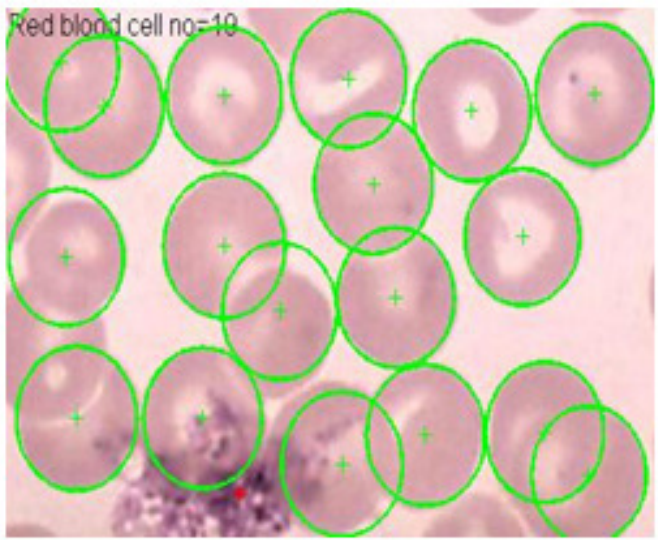

(e) Image 5

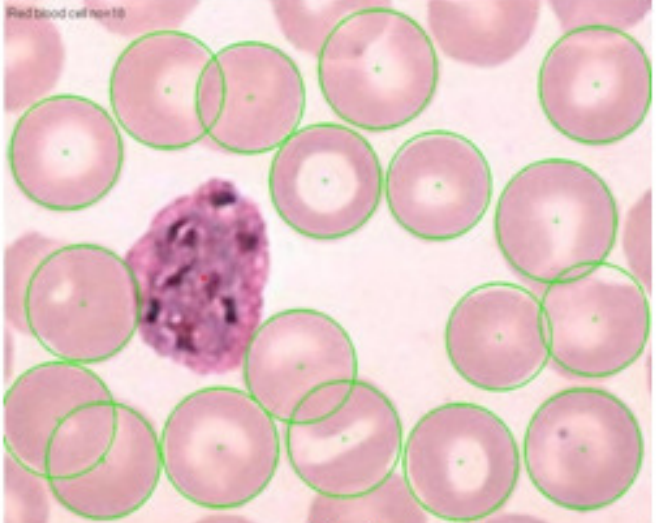

(b) Image 2

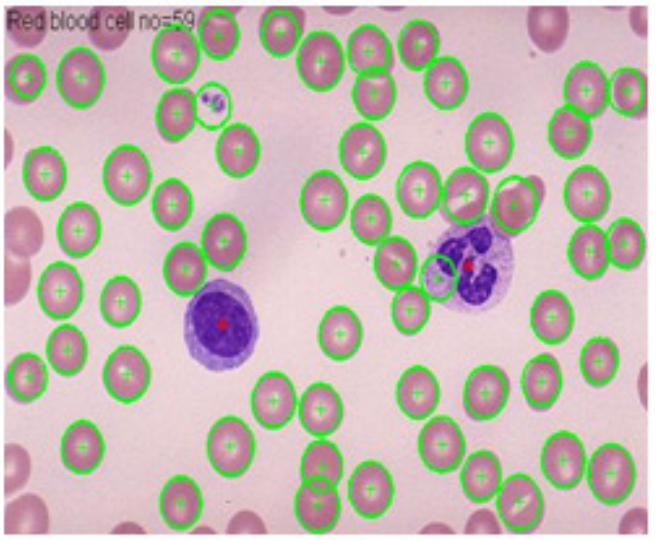

(d) Image 4

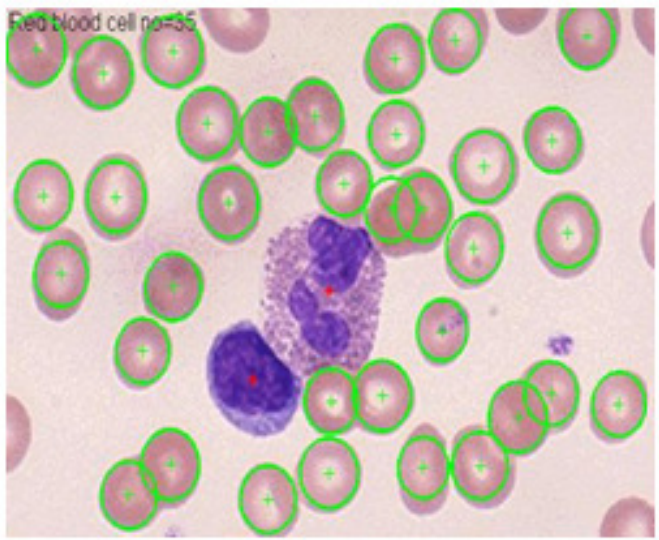

(f) Image 6 
Signal \& Image Processing : An International Journal (SIPIJ) Vol.3, No.2, April 2012

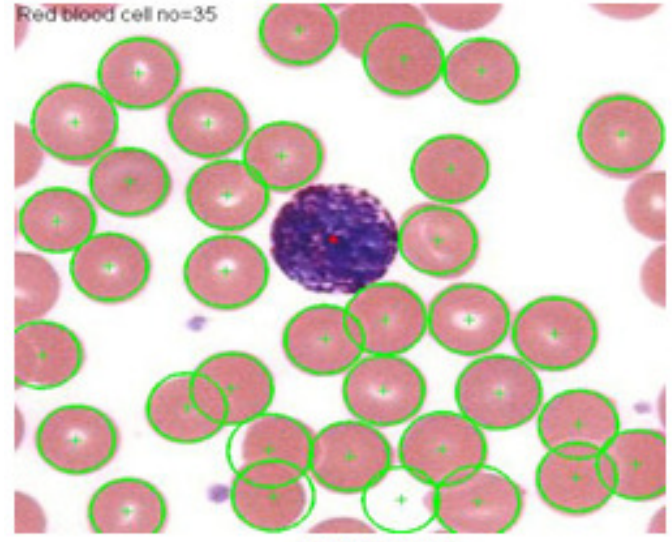

(g) Image 7

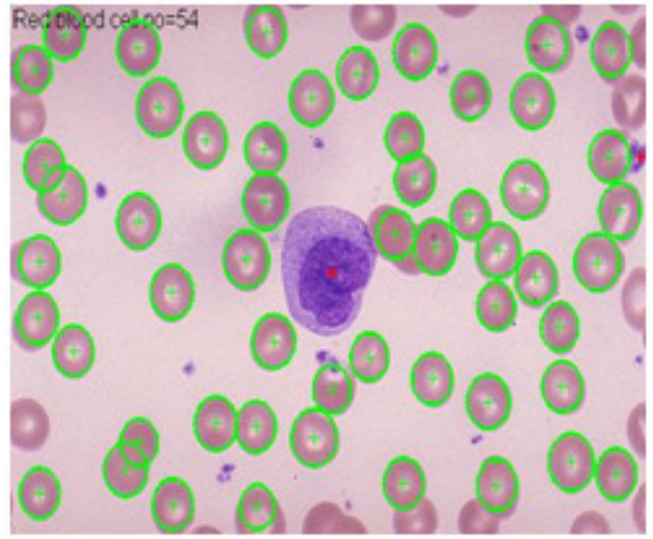

(h) Image 8

Figure 10: The results of 8 samples of red blood cells after performing Hough transform technique.

\section{CONCLUSION}

As a conclusion, this research successfully utilizes morphological approached for segmentation, extraction and estimation in order to solve problem in image processing of the red blood cells. The results of the image can be used as good input in determining the number of red blood cells by using Hough transform technique. By using the MATLAB, all the importance's aspects like correct algorithm and system has been successfully produced. With correct algorithm, the red blood cells can be detected and segmented as well as estimated the number of the red blood cells. Through system created using MATLAB, it also enable the study of the morphological features of the red blood cells image, thus, can determine whether the person is normal or otherwise by referring amount of red blood cells in human blood. This technique does not involve too much looping process when develops the MATLAB source code program. One of the issues that need to be considered to improve this study is to reduce the time taken by the user determine the red blood cells parameters.

\section{REFERENCES}

[1] Michael R. Pinsky, Laurent Brochard and Jordi Mancebo. "Applied Physiology in Intensive Care Medicine”. Springer. 229-238, 2007.

[2] Dondorp AM, Angus BJ, Chotivanich K, Silamut K, Ruangveerayuth R, Hardeman MR, Kager PA, Vreeken J,White NJ. "Red cell deformability as a predictor of anemia in severe falciparum malaria". Am J Trop Med Hyg 60: 733-744; 1999.

[3] Medicine Health - http://www.medicinehealth.com/leukemia/article.html.

[4] Yuzhang WEI. "The Research of Urinary Sediment Visual Component Analysis Based on Fuzzy Clustering”. Nanjing Information Engineering University, 2008:3-4,15-32.

[5] Ran Ding. "Algorithm Research on Recognition and Classification of Microscopic Urinary Sediment Images". Jilin University, 2006: 9-16, 20-31. 
Signal \& Image Processing : An International Journal (SIPIJ) Vol.3, No.2, April 2012

[6] C.D. Ruberto, A.G. Dempster, S. Khan and B. Jarra. "Segmentation of Blood Image using Morphological Operators". Proceeding 15th International Conference on Pattern Recognition. vol. 3, pp. 397-400, 2000.

[7] Tahir Rabbani and Frank van den Heuvel, "Efficient hough transform for automatic detection of cylinders in point clouds" in Proceedings of the 11th Annual Conference of the Advanced School for Computing and Imaging (ASCI '05), The Netherlands, June 2005.

[8] Roy A. Dimayuga, Gerwin T. Ong, Rainier Carlo S. Perez, Gefferson O. Siy, Saman C. Sohrabi Langroudi and Miguel O.Gutierrez. "Leukemia Detection Using Digital Image Processing in Matlab". ECE Student Forum, De La Salle University, Manila. March 26, 2010.

[9] Ramin Soltanzadeh. "Classification of Three Types of Red Blood Cells in Peripheral Blood Smear Based on Morphology. Proceedings of ICSP, 2010.

[10] Heidi Berge, Dale Taylor, Sriram Krishnan, and Tania S. Douglas. Improved Red Blood Cell Counting in thin Blood Smears. Proceedings of ISBI, 2011. pp.204-207.

[11] Zack G.W., Rogers W.E. and Latt S.A. "Automatic-measurement of sister chromatid exchange frequency.” Journal of Histochemistry \& Cytochemistry 25, 1977, 741-753.

[12] Guitao Cao, Cai Zhong,Ling Li and Jun Dong. "Detection of Red Blood Cell in Urine Micrograph". The 3rd International Conference on Bioinformatics and Biomedical Engineering (ICBBE). 2009.

[13] Centers for Disease Control and Preventation Public Health Image Library (online) http://phil.cdc.gov/phil/home.asp.

[14] Blood cell histology - http://www.unomaha.edu/hpa/blood.html

[15] University of Utah Libarary - http://library.med.utah.edu/WebPath/HEMEHTML/HEME005.html

[16] Kenneth. R. Castleman, Z. G. Zhu. "Digital Image Processing". Publishing House of Electronics Industry, Beijing, 1999.

[17] W. Meisel. "Computer-Oriented Approaches to Pattern Recognition". Academic Press. New York, 1972.

[18] Shapiro, Linda and Stockman, George. "Computer Vision". Prentice-Hall, 2001. 
Signal \& Image Processing : An International Journal (SIPIJ) Vol.3, No.2, April 2012

\section{AUTHORS:}

N. H. MAHMOOD received his B.Eng. and M.Eng. degrees in Electrical Engineering from Universiti Kebangsaan Malaysia (UKM) and Universiti Teknologi Malaysia (UTM) respectively. He obtained his Ph.D. degree from the University of Warwick, United Kingdom. His research areas are biomedical image processing, medical electronics and rehabilitation engineering. Currently he is a Senior Lecturer at Faculty of Health Science and Biomedical Engineering, UTM.

M. A. MANSOR received his B. Eng and M. Eng. in Electrical Engineering from Universiti Teknologi Malaysia (UTM). His research areas are biomedical signal processing and medical electronics. He is now serving as a tutor at the Faculty of Health Science and Biomedical Engineering, UTM for past 3 years.
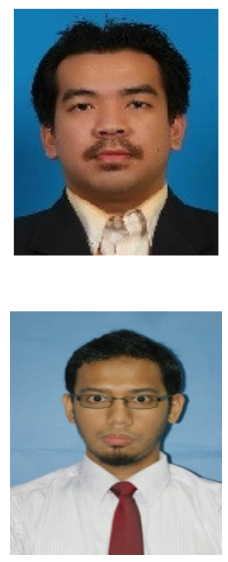